\title{
Antonio Machado o la representación simbólica del tiempo en "Soledades, Galerías y otros poemas”, (1907)
}

\author{
Víctor CANTERO GARCÍA* \\ IES “Fernando Savater”, Jerez de la Frontera (Cádiz)
}

\begin{abstract}
RESUMEN
El tiempo y la temporalidad, entendidos como conceptos filosóficos, son dos de los ejes vertebradores de la poesía de Antonio Machado. En el presente artículo se pretende poner de relieve la habilidad del poeta sevillano para trasladar a sus versos un pensamiento filosófico claramente bergsoniano, en el cual supo encontrar respuesta a muchas de sus preguntas sobre el sentido de la existencia y el destino del hombre en el mundo.

Tras analizar los elementos fundamentales de esta concepción temporalista de la poesía machadiana, el presente trabajo se centra en el descubrimiento de los elementos de la temporalidad que se contienen en determinados poemas de Soledades. Galerías. Otros poemas", (1907). Descubrimiento al que se llega por medio del estudio de los elementos simbólicos que nos remiten al tiempo, así como mediante el análisis lingüístico y estilístico de dichos poemas.
\end{abstract}

Palabras clave: tiempo, temporalidad bersgsoniana, filosofía, poética de Antonio Machado.

\begin{abstract}
The time and temporality, understood like philosophical concepts, are two of the essential axes of the A. Machado's poetry. In this article is tried to put of relief the Sevillian poet's hability to clear transfer to his verses the philosophical concept of Bergson about the time, in which he could fine answers to many of his questions about the meaning of existence and man's destiny in world.

After analyzing the fundamental elements of this temporalist conception of poetry, this work is concentrated on the temporality shades found in some poems of Solitudes. Galleries and other poems, (1907). Discovery which is reached through the study of simbolic elements which take us to the time and by means of the linguistic and stylictic analysis of these poems. Keywords: time, Bergson's temporality, philosophy, Antonio Machado's poetics.
\end{abstract}

* Doctor en Filología Hispánica por la Universidad de Cádiz. Investigador, miembro del Grupo Oficial de Investigación, Clave: HUM-141. Universidad de Sevilla. Catedrático de Literatura Española en IES. 
Sumario: 1. Introducción. 2. Machado y las claves filosóficas de la temporalidad: hacia un modo peculiar de concebir la poesía. 3. Análisis de los elementos que determinan el lenguaje poético de Antonio Machado. 4. Estudio de los elementos simbólicos y recursos lingüísticos que representan la "temporalidad" en Soledades, Galerías y otros poemas. 5. Conclusión.

\title{
1. Introducción
}

Cualquier investigador que haya pretendido escudriñar en los entresijos de la arquitectura poética machadiana se habrá hecho en más de una ocasión esta pregunta: ¿de dónde obtuvo el poeta la energía y la inspiración para lograr que sus versos sigan hoy contando con la frescura, el encanto y la atracción que los convierten en irresistibles para cientos de lectores?. Algún don especial poseía el escritor sevillano para dar a luz un lenguaje poético desnudo de artificio y rico en llamadas directas a la parcela más emocional del lector. Nos asombra la habilidad con la que este autor transforma la palabra en materia poética. Se trata de un ingenio muy especial, pues dar vida a las palabras y convertirlas en emociones, vivencias y sentimientos no es fruto de la improvisación; antes al contrario, es una condición muy personal, es un rasgo distintivo propio de un genio singular y un modo especial de ver el mundo y de sentirse visto por él.

Pues bien, tanto la curiosidad del investigador como el asombro del lector hacia el modelo poético representado por Antonio Machado no podían quedarse en simple anécdota. Se necesitaba buscar una explicación que justificase el poder de "enganche" de los versos machadianos, y a ello dedicamos la presente colaboración. Es decir, que en este artículo pretendemos aclarar las dudas y despejar las incógnitas a cerca de un procedimiento técnico, en virtud del cual, Machado nos ha legado un corpus poético cuya esencia significativa sigue palpitando en muchas de nuestras almas, a la par que el valor polisémico de los símbolos que en dicho corpus se emplean, sigue hoy teniendo plena vigencia. Dicho en palabras de Ricardo Gullón, lo que con el presente trabajo se pretende es:

\begin{abstract}
Abordar los poemas de Antonio Machado, desde la única vía posible: desde las palabras que los componen y con las que se expresan los sentimientos del poeta; si tiene acierto en la elección y disposición de esas palabras, conseguirá producir en el ánimo del lector una cascada de sensaciones, de las cuales importa sobre todo la emoción poética. (Gullón, 1949:567)
\end{abstract}

Esta capacidad de Machado para transmitir emociones al lector se sustenta en la creación de un leguaje poético basado en la plena sinceridad, en la completa espontaneidad y en una sencillez capaces de atrapar a aquellos lectores que buscan en sus versos el fondo significativo antes que los valores formales y estéticos. Nuestro poeta despoja su lenguaje de intenciones herméticas y lo hace cercano al habla corriente, a la par que infunde en cada palabra la significación normal, previsible e imaginable por el lector. Machado busca en todo momento que sus versos cuenten con claridad y transparencia, que sean capaces de expresar sin veladuras las 
emociones dónde arraiga cada poema y que ni nada ni nadie se interponga entre sus versos y quien los lea. En definitiva, la suya es una poesía que tiene poco de "poética" - entendiendo el término como elaboración artificial - y mucho de diáfana y sentimental. Una poesía con la que su autor nos propone que veamos lo que él quiere mostrarnos a través de ella.

Sin embargo, lograr que el lenguaje poético cale con tanta fuerza en el ánima del lector no fue tarea fácil para nuestro autor. Parece claro que Machado no utilizó en sus versos las palabras como objetos, prescindiendo de su significado, ni al modo de los prosistas, como mera designación de cosas encaminadas a expresar una idea. El poeta andaluz va por otro camino, pues es capaz de fundir, en un equilibrio de sencillez y armonía, la sensación y la palabra, lo que desea expresar y el vínculo donde transporta lo expresado: sus emociones. La vivencia y el lenguaje van de la mano, lo que dicho de otro modo implica que el poeta vive, siente y experimenta aquellas emociones que luego traslada a sus versos como cauce natural de expresión. En concordancia con este modo de hacer poesía, en sus textos no están presentes ni el pensamiento lógico ni el razonamiento; antes al contrario, en ellos tan sólo se insinúa, se sugiere para que el lector complete y ponga lo que le falta a cada poema que siempre nos da la impresión de estar inacabado y abierto. Al descubrimiento y análisis de este leguaje dedicamos el segundo objetivo de nuestro artículo.

De lo aquí expuesto se desprende que vivencias y lenguaje poético son dos realidades que viven en perfecto matrimonio: vida y poseía son en él dos caras de la misma moneda, las cuales son tan inseparables que la una no puede subsistir sin la otra. De acuerdo con ello, el tercer propósito de nuestra aportación se centra en ofrecer al lector una muestra representativa de cómo nuestro poeta supo trasladar al lenguaje poético una de sus mayores obsesiones: la temporalidad y la importancia del tiempo como factor determinante de nuestras vidas. Tan importante es el devenir temporal para Machado, que tal como sostiene Bárbara Philer:

Él era muy consciente de que todo artista está irrevocablemente arraigado en su tiempo y que sus creaciones no son otra cosa que la objetivación de su experiencia temporal. Esa sujeción del artista-poeta en el tiempo era para Machado una verdad axiomática ya que el poeta en el tiempo crea su mundo poético con ideas que no son categorías formales y lógicas, sino directas intuiciones del ser, de su propio existir. A través de estas intuiciones se convierte el tiempo en temporalidad. (Philer, 2003: 93)

Y, ¿qué mejor modo de hacer patente esta decisiva importancia de la temporalidad en la poesía machadiana que analizando los símbolos poéticos que la representan en algunos de los poemas más significativos de Soledades, galerías y otros poemas, (1907)? Este es el tercer cometido que nos proponemos en esta colaboración: descubrir e interpretar la carga simbólica de aquellos términos que mejor expresen el traslado al lenguaje poético del tiempo como tema recurrente. Términos que, entre otros son: la tarde, el agua, la fuente, el huerto, el viaje, etc. Es decir, que partiendo del concepto filosófico del tiempo establecido por Bergson, que con tanta fuerza arraigó en Machado, procedemos a comprobar cómo el poeta lleva a la práctica en sus 
poemas aquella definición de la poesía que él mismo expresó en más de una ocasión; a saber:

La poesía es arte temporal basado en la recurrencia de ciertos ritmos y en recursos técnicos que producen en el lector, y más aún en el oyente - pues la temporalidad de la lírica se percibe por el oído - la impresión de un devenir acontecido en el tiempo. La poesía es diálogo del hombre con el tiempo. Eso es lo que el poeta pretende eternizar, sacándolo fuera del tiempo. ( A. Machado: 1937: 410)

Mediante este ejercicio práctico este articulista pretende dar coherencia y dotar de un itinerario lógico a su tarea, la cual se inicia con la comprobación de la habilidad machadiana para transformar las palabras en lenguaje poético y acaba por la interpretación de sus versos al hilo de una de sus mayores preocupaciones: el devenir temporal, entendido como flujo ininterrumpido en el que la duración se convierte en la medida de la existencia. Y al acabar este recorrido, a buen seguro contaremos con nuevos elementos para comprobar lo que de cierto tiene la siguiente afirmación que Machado pone en boca de Juan de Mairena: la poesía es una arte temporal y la temporalidad propia de la poesía sólo puede encontrarse en sus versos plenamente expresada.

\section{Machado y las claves filosóficas de la temporalidad: hacia un modo peculiar de concebir la poesía}

Cuando Machado asiste al curso de filosofía impartido por Henri Bergson en el Colegio de Francia en París - curso académico 1910-1911 - busca mucho más que hacer un buen uso de la beca que le concedió la Junta de Ampliación de Estudios con el fin de perfeccionar su dominio del francés. Desde siempre nuestro poeta mostró un gran interés por encontrar en la filosofía respuestas a muchos de los enigmas de la existencia humana. Y tan grande es su afición por la filosofía que en Juan de Mairena, (1937), su principal obra en prosa, se retrata a si mismo como una especie de pedagogo socrático que conversa con sus discípulos en una clase imaginaria de Retórica y de Sofística. Pues bien, este interés fue dando como resultado la configuración de un pensamiento filosófico propio, el cual fue decisivo a la hora de abordar la poesía como creación personal, sincera, auténtica y cercana al lector.

Entre las muchas preocupaciones filosóficas que ocuparon la mente de Machado destaca su obsesión por desentrañar los misterios del tiempo, así como su inquietud por averiguar la decisiva influencia del devenir temporal en la creación poética. Sería pretencioso por nuestra parte intentar plasmar en este apartado todos los elementos filosóficos que conforman la temporalidad como concepto rector del pensamiento machadiano, tanto en lo que respecta a su propia visión de la existencia humana como en lo que atañe a su particular enfoque el arte poético, entendido éste como una disciplina hermanada con la filosofía. Es por ello que vamos a centrarnos en tres aspectos capitales; a saber: en primer lugar hemos de encontrar los motivos por los

${ }^{1}$ MACHADO, A. (1917): Poesías Completas, Madrid, Espasa-Calpe, 1981, p. 329. 
que Machado buscó desde joven en la filosofía explicación a sus interrogantes vitales; en un segundo momento hablaremos de los filósofos y de las ideas filosóficas con las que nuestro poeta se sintió más identificado; y en último lugar, pasaremos a especificar qué componentes de la temporalidad bergsoniana son trasladados por el escritor andaluz a su propia concepción de la poesía.

Tal como sostiene José María Valverde, nuestro poeta contaba ya desde joven con todo un conjunto de preocupaciones existenciales a las que va dando respuesta a medida que lee y estudia de forma concienzuada a los filósofos existencialistas franceses y alemanes, a la par que conoce las ideas aportadas por la fenomenología y la nueva metafísica: disciplinas en pleno auge a comienzos del siglo XX. Y una clara muestra de que Machado contaba con interrogantes existenciales, previos a su contacto con los movimientos filosóficos citados, la encontramos en su poema Yo escucho los cantos que en Soledades (1899-1907) se edita bajo el título Los cantos de los niños ${ }^{2}$. En este texto el poeta ya utiliza los símbolos poéticos del transcurrir del tiempo: el agua, la fuente, el sueño y la pena, entre otros, que luego volverán a aparecer de forma recurrente en sus poemas. Con ellos pretende exponernos su idea de la temporalidad, aquí tan sólo esbozada, pero que: alcanzará su total desarrollo y su plena aplicación a la lírica una vez que Antonio Machado conozca el pensamiento filosófico de Bergson. ${ }^{3}$ Parece claro que a nuestro poeta le acuciaban ciertos interrogantes a los que intentó responder bastante antes de conocer el pensamiento de Bergson, Heidegger, Proust o Joyce. Una muestra de ello la encontramos en su texto Elegía de un madrigal (1907), en el cual ya se atisban tanto la concepción psicológica del tiempo propia de Proust, como la particular estética del tiempo de Joyce o la relación que Bergson establece entre materia y memoria. Lo cierto es que tal como establece Eugenio Frutos, no es seguro que Machado hubiera leído a Bergson antes de 1910, aunque muchos de sus poemas de Soledades (1903) se podrían relacionar con su filosofía, por lo que: tal vez fue el bergsonianismo a priori de Machado en esos poemas, lo que le llevó a interesarse tanto, posteriormente, por la filosofia de Bergson. ${ }^{4}$

2 MACHADO, A. (1907): Soledades. Galerías y otros poemas. Ed. de Geoffrey Ribbans, Madrid, Cátedra, 2000, p. 95. Esta es la edición que utilizamos en la presente colaboración.

3 VALVERDE, J. M. (1989): “Antonio Machado, poeta pensador”, en A. Machado: el poeta y su doble. Intervención en Congreso Internacional sobre A. Machado. Universidad de Barcelona, Dpto. de Filología Española, p. 56.

4 FRUTOS, E. (1960): "El primer Bergson en Antonio Machado" en Revista de Filosofia, XIX, 73-74, p. 119. Por otro lado, un estudio muy completo sobre el interés que desde joven despertaron en Machado las figuras de Marcel Proust y James Joyce nos lo ofrece Marisol Morales Ladrón, la cual sostiene que: Machado dedicó muchas referencias a estos dos últimos en su Proyecto de discurso de ingreso en la Real Academia (1931), alli alude a sus obras por considerarlos en el sentido más bergsoniano ejemplos de poetas de la memoria y de la percepción. Cfr. Morales Ladrón, Marisol (2004): "La temporalidad bergsoniana en la estética de Antonio Machado y James Joyce" en BELL, Barcelona English Language and Literature, 13, p. 2. 
Además de los antecedentes citados, no podemos olvidar que Machado siempre manifestó un especial afán por acabar con la angustia existencial que le acompañó a lo largo de su vida. Y dicha angustia se manifiesta en su búsqueda de la otredad; es decir: en salir de su "yo" subjetivo y poético y proyectar ambos en el "otro". Nuestro poeta apuesta por la heterogeneidad del ser y por la dialéctica del "yo" frente al "otro" como fórmula para salir de su aislamiento y soledad, proyectándose en los "otros" a través de sus versos. Este abandono progresivo del "yo" intimista y sentimental propio de Soledades (1903) para pasar al "tú" objetivo de Campos de Castilla (1912) y terminar en el "nosotros" de Nuevas Canciones (1924) y Cancionero apócrifo (1924-1926) es todo un ejercicio de autoanálisis y de eliminación de la angustia y la desazón personal. Eliminación a la que contribuye el hecho de que Machado hiciera suyo el concepto bergsoniando de la temporalidad entendida como "duración" del ser en el tiempo. O dicho de otro modo: que lo que somos - nuestra esencia - permanece frente a nuestra existencia que es limitada. Un hallazgo que trasladado al ámbito de la creación poética supone hacer que la poesía equivalga a "palabra en el tiempo". Palabra que tiene vocación de permanecer en el tiempo más halla de la muerte del poeta, por ello nuestro autor mantiene ese comportamiento dialógico en sus textos, ese deseo de proyectarse en los otros, ese afán de dejar de ser "yo" para ser los "otros yos", los cuales vivan como suyos los versos que él escribe. Pues bien, este modo de actuar, en opinión de Armando López Castro: encuentra su justificación en las lecturas que Machado hizo de la filosofía existencialista y fenomenológica, difundidas por Europa tras la primera guerra mundial como superadoras del subjetivismo idealizante y defendidas por Buber, Marcel, Bakhtin y Bergson. ${ }^{5}$

Conocida la predisposición de Machado a buscar en la filosofía respuesta a las cuestiones vitales, veamos ahora los principios filosóficos y los autores con los que se sintió más identificado y de los que supo obtener un importante rédito a la hora de explicar su quehacer poético en clave de "temporalidad". Y el primero de dichos conceptos es el de la "duración" o devenir en el tiempo, propio de Bergson. Este filósofo determina que existen dos tipos de tiempos; a saber: el tiempo exterior, cronológico y que se corresponde con la lógica y el tiempo interior, que es el ámbito de la intuición. De aquí nace la oposición razón-intución, según la cual la lógica y los conceptos abstractos son elementos estáticos que impiden el fluir constate de la realidad y no nos transmiten la sensación de cambio. Por contra, la intuición es capaz de sobreponerse a la razón y captar la realidad sin sujetarse a los principios lógicos. La intuición dirige el flujo de nuestra conciencia y conforma la realidad de cada momento. Pues bien, Machaco conoce esta antítesis bergsoniana entre razón e intuición y apuesta por la segunda, entendida como libre fluir del pensamiento, a la hora de explicar la génesis de la creación poética. A partir de esta primacía de la intuición sobre la razón, nuestro poeta interpreta sus creaciones literarias como objetivaciones de su experiencia temporal, a la vez que convierte la sujeción del artista -aquí poeta- al poder absoluto del tiempo en el eje axiomático de su

5 LÓPEZ CASTRO, A. (2006): “Antonio Machado y la búsqueda del otro” en Estudios Humanísticos. Filología, 28, p.27. 
concepción del arte. En este sentido encuentra su explicación la afirmación machadiana de que: el poeta lo es en el tiempo. Es decir, que tal como sostiene Bárbara Pihler, para Machado: el poeta crea en el tiempo su mundo poético con ideas que no son categorías formales lógicas, sino con intuiciones directas del ser, de su propio existir. (Philer, 2003: 93). Y esta supremacía de la intuición sobre la razón llevará a Machado a buscar su propia metafísica del tiempo, la cual ha de surgir del trabajo conjunto entre filósofos y poetas. Una colaboración en la que nuestro poeta creía firmemente, pues como nos indica Juan López-Morillas, para Machado: la unión del filósofo y del poeta se producirá en el campo de la interpretación temporal de la realidad. (López-Morillas, 1979: 256)

Sin embargo, con ser importante para nuestro autor este triunfo de la intuición sobre la razón, no es el único concepto filosófico que heredará de Bergson. El segundo principio bergsoniano que Machado hace suyo es la "dureé" entendida como existencia del hombre en el tiempo, un tiempo que está medido y contado y contra cuyo punto final nada podemos hacer. Por ello el tiempo es aliado de la muerte, teje nuestra vida en su permanente devenir y nos acerca a la muerte como el final de nuestro vivir. Esta idea de la caducidad de nuestro tiempo vital es la que provoca en Machado la escritura de unos versos cargados de deseos de eternidad, de ansias de perpetuar en el tiempo sus deseos, amores, sentimientos, pasiones y vivencias. De aquí que en Soledades, galerías y otros poemas (1907) nuestro autor nos ofrezca el muestrario de una lírica carga de humanidad, de cercanía a la vida real de los hombres y mujeres, de proximidad al sentir y al vivir de sus congéneres. Es él como poeta y como ser humano quien se quiere eternizar en nosotros a través de sus versos. Un deseo que aún siendo muy legitimo no será capaz de impedir que llegue nuestro final, pues como el propio poeta sostiene: vivir es esperar un desenlace previsto. Esta concepción del tiempo, entendido como breve lapsus vital durante el que permanecemos vivos, ya había sido llevada a la lírica por poetas tan famosos como Jorge Manrique, quien, a juicio de Machado, es un de los poetas españoles que mejor ha hecho de la poesía un arte temporal al trasladar a sus versos la intensa y profunda impresión del tiempo, aquella que capta y fija una auténtica intuición poética hecha arte. Y este es justo el alcance que nuestro autor quiere dar al tiempo en sus versos, empresa en la que no descansó hasta lograrlo, pues tal como señala Francisco Ayala:

\begin{abstract}
Machado pasó su vida entera preguntándose en su soledad por cuestiones capitales, y por las eternas cuestiones del ser y del tiempo. Ha golpeado incansablemente en las puertas del misterio; ha tendido oídos a todos los aldabonazos, a todas las señales, al corazón de todos los relojes, y con tan manifiesto anhelo metafísico ha preguntado, que más de una vez hendió la tiniebla su patética urgencia y el poeta extrajo frutos que suelen ser reservados no a su clarividencia, sino a la exploración metódica del filósofo. (Ayala, 1975: 90-91)
\end{abstract}

De lo hasta aquí expuesto se infiere un tercer componente del pensamiento bergsoniano que es asumido por Machado; a saber: la visión intuitiva de lo real y de la acción. Visión que posibilita al artista, y más aún al poeta, a captar el tiempo cualitativo de la duración por medio del don de la intuición. Este don, que no es 
intelectual, faculta al artista a comprender la realidad en el flujo temporal de los hechos y no por medio de un análisis lógico y formal. De acuerdo con ello, para Machado lo intelectual no tiene cabida en la lírica, la cual es un arte intuitivo y como tal no sólo es metafísicamente viable, sino históricamente posible y oportuna. Así lo pone de manifiesto nuestro poeta al poner en boca de Juan de Mairena afirmaciones como las que a continuación se citan:

El hombre de nuestro siglo ha sido un sedicente anfant du siècle, ha hablado de un mal de siglo. De este modo ha expresado, más o menos conscientemente, una vocación hacia la temporalidad que no es propia de todos los tiempos. Esta especial vocación se descubre más que nada en la excepcional trascendencia que el hombre ha atribuido a la música y a la poesía lírica, que son las artes temporales por excelencia. (Machado, 1940: 521)

Sabidos los principios de la filosofía bergsoniana que Machado hizo suyos, pasamos en un tercer momento ha considerar cuáles de ellos convierten a la temporalidad en el eje rector de su lírica. Y la primera afirmación que el poeta traslada a su propio modo de escribir versos es la de hacer de la poesía un diálogo del hombre con el tiempo. Según la misma, el poeta alimenta sus creaciones de todos los hechos que han sucedido y suceden en el tiempo: recuerdos, sueños, evocaciones, etc. Esta concepción de la poesía como arte temporal es una convicción profunda del poeta, y como tal la expresa al decirnos que el arte poético:

Está basado en la recurrencia de ciertos ritmos y en recursos técnicos que producen en el lector - y más aún en el oyente, pues la temporalidad de la lírica de percibe sobre todo por el oído - la impresión de un devenir acontecido en el tiempo. (Machado, 1936: 298)

Y dicho devenir no es otra cosa que la propia vida de cada hombre ligada al tiempo, por ello Machado se preocupa en sus poemas del hombre concreto, del individuo particular con sus problemas y angustias y no del ser humano en general.

Y nuestro poeta logra que su poesía sea un auténtico diálogo con el hombre en un tiempo y un espacio concretos, un diálogo en el que sus versos representan la expresión de los sentimientos, dudas, temores, pasiones, amores y desengaños propios de todo ser humano. Hablamos de un modo de hacer poesía en el que el poeta recurre a los sueños, a los recuerdos y a la evocación de las imágenes que nos vienen a la mente al rememorar lo vivido; es decir, es esta una poesía en la que se evitan los conceptos, los razonamientos formales, la lógica o las argumentaciones. Nos introduce Machado en un modelo poético en el que privan unos versos llenos de plasticidad, de alusiones, evocaciones, intuiciones que logran que su poesía evite la artificialidad y el edulcoramiento propio de otros poetas. Nuestro autor rechaza la esclerosis paralizante y el afán conceptista propio de otros cánones poéticos y ello porque, tal como señala Manuel Ángel Vázquez Medel: toda la poética machadiana puede ser comprendida como ese anhelo de pescar peces vivos, de atrapar el 
movimiento aunque -heraclitiano- como es, sabe que es imposible del alzar el vuelo, sin detener la libertad del pájaro. (Vázquez Medel: 1997: 1086)

Una vez que el poeta establece su quehacer poético sobre la base de este diálogo con el hombre en el tiempo, el segundo elemento de la filosofía bergsoniana que traslada a sus versos es el de la "movilidad", el "cambio", "la renovación" y la "regeneración" que tanto los hombres como las realidades que nos rodean experimentan en el devenir del tiempo. En esencia somos los mismos y sin embargo el paso del tiempo va cambiando nuestro modo de estar en el mundo. Este modo de entender el efecto de la temporalidad en nuestras vidas es plasmado por Machado en un estilo de hacer poesía en el que los sueños, los recuerdos y las evocaciones hacen que el ser humano contemple el pasado desde el presente; es decir: examine los cambios que el paso del tiempo ha provocado en su vida y añore todo lo que de bueno ha vivido, dejando en el olvido los fracasos y las desilusiones. En definitiva, nuestro poeta escribe unos versos en los que domina el deseo de encontrarse con el hombre cara a cara, de hablarle con sinceridad y trasparencia y de sentirse hermanado con quien como él siente en sus carnes el paso del tiempo. Nos referimos a un modo de hacer poesía que, tal como sostiene Bernarado Gicovate: confiere a su obra una unidad y una autenticidad que son las dos virtudes más buscadas en este poeta. (Gicovate: 1979: 244). Virtudes que: junto a la preocupación por lo temporal confieren a la poesía de Antonio Machado aquella unidad capaz de articularla de una manera más orgánica. (Zubiria, 1959: 208).

Esta necesidad de tender lazos hacia el "otro" marca la dirección que la poesía de Machado ha de tomar con el paso de los años. Un cambio que se concreta en el abandono de sus postulados subjetivistas propios de Soledades (1903) para pasar a una comunicación con el "otro" en Campos de Castilla (1912). El poeta sale de sí mismo y busca en los "otros" todo lo que le llama, lo que le requiere, le provoca e incita a escribir sus versos.

\section{Análisis de los elementos que determinan el lenguaje poético de Antonio Machado}

Escribir poesía es dotarse de un leguaje personal, auténtico y original que sea capaz de atrapar al lector. Ésto lo sabe muy bien nuestro autor, quien en sus versos supo mantener el difícil equilibrio entre su entusiasmo por la filosofía y su deseo por llegar a los más recónditos lugares - galerías - del alma de sus lectores. Equilibrio que sólo puede ser duradero si se cuenta con un lenguaje sencillo y directo, capaz de provocar en el lector las mismas inquietudes, anhelos y deseos que el poeta experimenta. Y esta habilidad para lograr que el lector vibre, se conmueva, se estremezca con lo que el poeta le dice se debe al uso por parte de Machado de un lenguaje directo y abierto a distintas interpretaciones, un lenguaje que invita a cada lector a participar en la recepción del mismo con el fin de interactuar y completar de modo personal aquello que las palabras y los versos son capaces de evocarle. En otras palabras, estamos hablando de un lenguaje poético, gracias al cual nuestro escritor pone en práctica la llamada "estética de la recepción", que no es otra cosa que la posibilidad de que toda obra literaria sea interpretada y completada por cada lector. 
Una participación del lector en el texto literario que, a juicio de Hans Robert Jauss implica que:

No exista ninguna obra literaria cuya vida no se geste sin su lector. La obra literaria no es algo independiente y autónomo que ofrece las mismas cosas en cada momento de la historia, sino que se realiza de diversas maneras dependiendo del diálogo con el lector. De acuerdo con ello, la función social de la literatura sólo se hace manifiesta en su genuina posibilidad allí donde la experiencia literaria del lector tiene claras implicaciones en su vida práctica, preforma su comprensión del mundo y con ello repercute en sus formas de comportamiento social. (Jaus, 1986: 201)

Esta estética que solicita la complicidad entre autor y lector es la que despliega Machado en sus poemas, dejando en cada caso que sea la capacidad interpretativa del lector la que complete la significación del texto, pues tal como señala Wolfgang Iser:

Si el texto es una combinación de letra y palabras, entonces debe ofrecer un espacio sistemático a quien realice dicha combinación. Y ello es así porque la mente humana no percibe los objetos del mundo como trozos o fragmentos sin relación entre sí, sino como configuraciones de elementos, temas o todos organizados y llenos de sentido. (Iser, 1997: 263)

Consciente Machado de que el lector es el agente fundamental que cierra el círculo de la creación literaria y confiere a sus poemas múltiples y variadas significaciones, crea un lenguaje poético en el que lo esencial es el acierto del poeta en la elección de cada una de las palabras que integran sus versos. Para nuestro escritor la verdadera preocupación del poeta debe ser el dominio de las palabras hasta el infinito; es decir, que el poeta debe ser capaz de poner la palabra en todo momento al servicio de sus intenciones, convertirla en un instrumento capaz de dar mil formas distintas a todos sus sentimientos. Por ello Machado está convencido de que los poemas se hacen con palabras y no con ideas, lo que significa que para él la poesía no ha de pretender transmitir grandes pensamientos, sino que tiene que infundir en el lector vida, pasión, sentimiento y emoción. Dicho de otro modo, el poeta aquí estudiado entiende que los versos, en su contenido formal, sí nos comunican ideas, pero lo más importante no son las ideas sino con qué palabras se nos presentan.

Para Machado la tarea primaria del poeta es descubrir el valor poético de las palabras por medio de su intuición, lo que equivale a contar con la pericia necesaria para hacer de las palabras recursos al servicio de la expresión verbal de sus sentimientos. Por ello, este esfuerzo por hacer de la palabra la protagonista de su estética poética obliga a nuestro autor a crear un lenguaje que explote al máximo la capacidad simbólica y expresiva de cada término, sin tener necesidad de embellecerlo o recargarlo conceptualmente. Se trata de un lenguaje ágil, suelto, libre de ataduras, contrario al culto por lo clásico en el idioma y cercano a la sencillez con la que el léxico de nuestra lengua es capaz de evocar sentimientos y despertar imaginaciones. 
Un lenguaje propio al que el poeta se refiere en su ensayo titulado Reflexiones sobre la lírica (1925) con las siguientes palabras:

Para expresar mi sentir tengo el lenguaje. Pero el lenguaje es mucho menos mío que mi sentimiento. Por de pronto he tenido que adquirirlo. Por ello, el lenguaje antes mío era de ellos, de ese mundo que no es ni objetivo ni subjetivo, tercer mundo en el que todavía no ha reparado suficientemente la psicología, el mundo de los otros yos. (Machado, 1925: 76)

$\mathrm{Y}$ este leguaje, que es transmisor de sentimientos, es el que pone a Machado en comunicación permanente con el lector. Nos referimos a un modelo lingüístico capaz de expresar emociones en estado puro a través de una cuidada selección de las palabras, las cuales jamás se interponen entre el poeta y su público. En definitiva, nos referimos aquí a lo que T. S. Eliot entiende por poesía libre de todo lo "poético", poesía que se yergue sobre sus huesos desnudos. Una poseía tan transparente que tan sólo vemos en ella lo que el autor nos quiere decir. Esta concepción de la poesía es la que asume Machado, a quien la palabra no le preocupa en sí misma, sino en cuanto materia fundamental de cada poema. Nuestro poeta supedita cada palabra a sus intereses expresivos, ya que su intención es lograr una adecuada expresión de lo que siente mediante el uso de vocablos que aparezcan en el texto enlazados de forma natural y espontánea. En consecuencia, nuestro escritor usa un lenguaje sencillo en las formas, pero profundo y meditado en el fondo, exento de adorno innecesario, pues tal como sostiene Guillermo de la Torre, Machado tenía muy claro qué tipo de lenguaje poético era el suyo. Y a las cualidades de dicho lenguaje alude nuestro poeta en la siguiente cita recogida por el autor antes nombrado:

En la lírica, imágenes y metáforas son de buena ley cuando se emplean para suplir la falta de nombre propios y de conceptos únicos que requiere la expresión de lo intuitivo, nunca para revestir lo genérico y lo convencional. Los buenos poetas son parcos en el empleo de metáforas, pero sus metáforas, a veces, son verdaderas creaciones. (Machado, 1916: 68) ${ }^{6}$

Unas cualidades que subrayan la importancia de lo intuitivo frente a lo racional a la hora de inspirar la creación poética de nuestro autor, el cual, en opinión de Gerardo Diego nos regala en sus obras: machismos versos tersos, horizontales, con pocos acentos y facilísima fluidez susceptible de ligereza; pero siendo los más típicos de los suyos versos esculpidos, gramáticos y enfáticos, es decir; fieles a la vocación sentenciosa y rotunda del poeta. (Diego: 1949: 271)

6 Señala Guillermo de la Torre que esta anotación procede de la obra de Machado titulada Los complementarios, 1916. En dicho texto hizo Machado algunos comentarios al libro de Vicente Huidobro titulado Ecuatorial, entre los cuales está el que aquí se cita. Cfr. DE LA TORRE, G. (1979): “Teoría literaria de Antonio Machado" en Antonio Machado: el escritor y la critica. Ed. de Ricardo Gullón y Allen W. Phillips, Madrid, Taurus, 1979, p. 237. 


\section{Estudio de los elementos simbólicos y los recursos lingüísticos que representan la "temporalidad" en Soledades, galerías y otros poemas (1907).}

Tal como indicamos en nuestra exposición de motivos dedicamos este apartado para pasar del la teoría a la práctica, de la arquitectura mental de la que Machado se sirvió para escribir sus versos al análisis de los mimos bajo el prisma de la temporalidad. Resulta obvio que en este breve espacio hemos de limitar nuestro análisis a un grupo reducido de poemas, no más de tres, con el que ofrecer al estudioso una muestra representativa de cómo nuestro poeta dejó la impronta temporal en Soledades, (1903) poemario luego incluido en la edición más completa y titulada Soledades, galerías y otros poemas (1907). Una impronta, que a juicio de Daniela Capra:

Es el principio rector de su poética, y está presente en ella a partir de las primeras composiciones que se publican a finales de 1902, y que constituyen el primer núcleo de Soledades. Años más tarde vio la luz Soledades, galerías y otros poemas, obra en la que vienen a consolidarse tendencias anteriores a la vez que se eliminan acentos quizá demasiado recargados. (Capra: 2003: 1)

A este mismo principio rector se refiere Bárbara Philer cuando sostiene que: la verdadera raíz de la creación poética y del pensamiento machadiano es el tiempo y la profunda impresión de la temporalidad que emana de los versos del poeta, la cual ha de añadirse a su continuo esbozo teórico sobre el fundamento temporal del la poesía. ${ }^{7}$ Un principio que con ser muy importante no lo es todo en la poesía de Machado, pues como él mismo sostiene:

El elemento poético no es la palabra por su valor fónico, ni el color, ni la línea, ni un complejo de sensaciones, sino que es una honda palpitación del espíritu; para $\mathrm{mi}$, el elemento poético es lo que pone el alma, es la voz propia del poeta, es la respuesta animada del poeta a su contacto con el mundo. Yo pensaba que el hombre puede distinguir la voz propia de los ecos inertes, que puede también, mirando hacia dentro, vislumbrar las ideas coordinando los universales del sentimiento. ${ }^{8}$

De lo anterior se desprende que si bien la temporalidad es la columna vertebral de su poesía, Machado entiende que por si misma no es suficiente para dotar a sus versos de las emociones, las palpitaciones y las vibraciones que los conviertan en un reclamo vivo e irresistible para sus lectores. Hace falta dotar a esos versos del pálpito vital, del cúmulo de sensaciones que les otorguen vida propia. De esta conjunción entre su preocupación por el devenir temporal y su afán por hacer de sus versos un testimonio vital surgen los poemas a cuyo análisis dedicamos aquí nuestra atención.

Y comenzamos el mismo por el que lleva por título La tarde. Es el poema VI de la edición de Soledades, galerías y otros poemas (1907) que en esta ocasión utilizamos.

${ }^{7}$ PHILER, B. art. cit. p.93.

8 MACHADO, A. Obras Completas, Madrid, Espasa-Calpe, 1989, p. 1802. 
A modo de muestra se reproducen tan sólo las dos primeras estrofas de dicho poema, remiendo al lector a las páginas 90-92 de la edición de Geoffrey Ribbans en su momento aludida:

\section{La tarde}

Fue una clara tarde, triste y soñolienta tarde de verano. La hiedra asomaba al muro del parque, negra y polvorienta...

La fuente sonaba

Rechinó en la vieja cancela mi llave; con agrio ruido abrióse la puerta de hierro mohoso y, al cerrarse, grave golpeó el silencio de la tarde muerta.

\section{$A$. Concreciones de la temporalidad que configuran el tema central del poema.}

Tal como sostiene Tesi Olcay: el tema central del poema es la pregunta de Machado sobre las condiciones que hacen soportable la vida humana: el cotidiano vivir, la muerte y el tiempo. El poeta se pregunta: ¿es preferible que tengamos una conciencia permanente de lo que ha sido nuestra vida o es mejor olvidar lo que fuimos y mirar al futuro? (Olcay: 2005: 2006). En este poema Machado recurre a la evocación del pasado desde el presente y pretende reproducir con tintes de inmediatez temporal una experiencia pasada: su encuentro con la fuente, testigo de sus amores y vivencias juveniles. Se trata de una experiencia que el poeta pretende rememorar y describir ahora con la misma plasticidad y carga emotiva con las que en su día vivió aquel momento irrepetible.

Esta rememoración del pasado desde el presente se representa en estos versos por medio del diálogo sereno entre la fuente, calificada de "hermana" y el poeta, quien se identifica como "hermano". Un diálogo que subraya el devenir temporal de los hechos contados mediante el uso de tiempos verbales que nos remiten al pasado - caso del pretérito perfecto: la fuente sonaba (v.4, estrofa $1^{\mathrm{a}}$ ) - a la par que nos ubican en el hoy, con el uso del presente: ...j. te recuerda, hermano, / un sueño lejano mi canto presente ( vv. 1-2, estrofa $4^{\mathrm{a}}$ ). El uso de los tiempos verbales como marcadores temporales determina una temporalidad externa, pues lo que de verdad intenta el poeta es borrar las fronteras temporales entre lo que fue el ayer: una alegre leyenda olvidada, (v. 4, estrofa 10a), lo que es el hoy: el fruto maduro pendía en la rama / lo mismo que ahora, ( vv. 4-5. estrofa $7^{\mathrm{a}}$ ) y lo que será el mañana: Adiós para siempre, la fuente sonora, / del parque dormido eterna cantora, ( vv. 1-2, estrofa 14a). Todo ocurre ahora, en el instante presente, todo pasa por su mente como un continuo cuyo punto final tan solo lo pondrá la muerte.

\section{B. Elementos simbólicos que evidencian la temporalidad a lo largo del poema:}

Utiliza Machado en este poema una fórmula de apertura y cierre con la que contener en el espacio y en el tiempo esa experiencia irrepetible de su primer encuentro amoroso en ese mismo parque. El hecho de repetir la misma estrofa al 
inicio y al final del texto delata su afán por atrapar el tiempo, por reproducir en el hoy lo vivido en el ayer. Por ello, el poeta nos invita a acompañarle en el viaje que comienza al "abrirse" la puerta y acaba con el "cierre" de la cancela mohosa. Un viaje que visto desde el hoy simboliza el paso irrecuperable del tiempo desde una juventud cargada de ilusiones, que no volverá, a una senectud plagada de sinsabores, que cada instante que pasa acerca más al poeta a la muerte. Esta es la esencia de unos versos que no sustraemos a reproducir:

Rechinó en la vieja cancela mi llave; con agrio ruido abrióse la puerta de hierro mohoso y, al cerrarse, grave golpeó el silencio de la tarde muerta.

En este recorrido, que pretende fundir el pasado con el presente, Machado va desgranando un conjunto de símbolos, de cuya significación temporal vamos a dejar constancia a continuación:

1. la tarde: constituye el marco temporal de referencia de la acción, y en el poema representa la hora de la tristeza, de la melancolía, del decaimiento. Es la hora triste y soñolienta $\left(\mathrm{v}, 1\right.$, estrofa $\left.1^{\mathrm{a}}\right)$ que hoy invita al recuerdo de lo que hace tiempo sucedió en ese mismo parque, en otra tarde, esta vez calificada de clara $\left(\mathrm{v} .1^{\mathrm{o}}\right.$, estrofa $\left.12^{\mathrm{a}}\right)$. El ayer es recordado desde el hoy, y ello con la pretensión de recuperar esa misma pasión, el mismo fuego amoroso con el que los labios del poeta besaron en su momento la linfa de la fuente: tus labios besaron mi linfa serena / y en la clara tarde, dijeron tu pena, (vv. 3-4, estrofa $12^{\mathrm{a}}$ ). Pero nada es ya igual, nada se puede repetir.

2. Ia fuente:_es el símbolo temporal por excelencia del poema. La fuente representa el eterno devenir del tiempo, pues: el agua cantora / -que- me guió a la fuente, (vv. 2-3, estrofa $3^{\mathrm{a}}$ ) entona hoy la: misma copla borbollante, (v. 2, estrofa 12a) que ayer. Por ello, la fuente con su surtidor de agua es depositaria de la memoria, en ella se contiene todo el pensamiento del poeta y todo el tiempo que ya no puede volver y recuperarse. Ese tiempo perdido es simbolizado por las muescas que produce el agua al caer sobre el blanco mármol al vertir sobre él: su melancolía, ( v. $4^{\mathrm{o}}$, estrofa $3^{\mathrm{a}}$ ). Machado recurre a la fuente y al agua como símbolos del ciclo eterno del devenir temporal. El poeta busca con ansia aquello que mitigue su dolor y su amargura: un mirto, un canto, una copla corriente, un cristal de alegría, un ensueño, un amor, una alegría olvidada y una fuente bermeja. Y todo ello pintado en sus versos como un sueño impresionista, calificativo con el que Bernard Sesé define este poema y al que alude con las siguientes palabras:

Evocación melodiosa en la que la música de las de sonoridades suaves o líquidas sugiere acertadamente, utilizando la armonía imitativa, el murmullo del agua que se va amplificando. Pero también evocación muy visual y plástica, en la que las palabras, más que el dibujo de una forma precisa, sugieren un color que las contiene y las desborda, como en un cuadro impresionista. ( Sesé, 1980: 143). 
3. el agua: el agua simboliza el eterno fluir temporal, concepto que Machado tomó de Heráclito. El agua es testigo mudo que canta la: copla borbollante/-que- me guió a la fuente. (vv. 2-3, estrofa $3^{\mathrm{a}}$ ). El agua es el cristal de la fuente, es ella quien dialoga con el poeta y le hace recordar que este momento ya lo ha vivido antes: $¿$ Recuerdas, hermano?.../ fue esa misma tarde de verano. (vv. 5-6, estrofa, $7^{\mathrm{a}}$ ). El agua representa: el claro cristal de alegría, (v.1, estrofa 9a), el cual en el pasado se hizo eco de los momentos felices vividos por el poeta y que hoy vuelve a ser confidente de sus penas. Es un agua que tiene vida propia y rasgos femeninos, son: bellos espejos cantores, (v.1, estrofa $10^{\mathrm{a}}$ ) que hoy como ayer susurran al oído del poeta: su alegre leyenda olvidada, (4, estrofa $\left.10^{\mathrm{a}}\right)$.

Gracias al recuerdo, la alegría se hace aquí de nuevo presente, se evocan los felices momentos pasados y Machado se reencuentra y se reconoce en este momento mágico de la unión del pasado con el presente.

\section{Presentación de los recursos lingüísticos propios de una lírica natural, sencilla y transparente:}

El dialogo entre el poeta y la fuente es el eje vertebrador de un poema, en el que Machado recurre a un lenguaje fresco, vivo y espontáneo para representar con sus versos una escena tan personal como sonora y colorista. Recurre el poeta a la prosopopeya para ofrecernos esta conversación entre la fuente -origen del agua- y y su "yo" lírico. ${ }^{9}$ Es este un recurso de estilo que dota al poema de un marco intimista y reservado, en el que los protagonistas de la acción se le presentan al lector por medio de los siguientes recursos lingüísticos:

\section{a. Para el marco temporal y físico: "la tarde"/ "el parque":}

Ambos elementos se presentan al lector con adjetivación abundante y de significado negativo. Mientras la tarde es lenta, triste, soñolienta, el parque es pintado como un lugar casi abandonado al que se accede por una cancela vieja que se abre con agrio ruido y que al cerrarse grave golpea el silencio de la tarde clara pero muerta. Todos los epítetos reflejan el estado de ánimo del poeta, quien desde su pena más honda, desde el dolor y la amargura que inundan su alma busca un atisbo de alegría en aquellos elementos naturales que en tiempos pasados dieron cobijo a sus gozos.

\section{b. Para la presentación de dos seres con vida propia: "la fuente"/“el agua":}

En medio de este marco físico en el que todo suena a desolación, la fuente y el agua toman vida propia y simbolizan la fugacidad del tiempo y la fusión en un solo instante temporal de lo vivido en el pasado y de lo que ahora se recuerda. La fuente y el agua son los dos protagonistas vivos, inmutables, permanentes con los que el poeta dialoga, en los que busca consuelo y con los que se recrea mediante el uso de un

9 Tal como precisa Antonio Sánchez Barbudo, en este poema Machado utiliza el monólogo interior como recurso estilístico: una técnica que a partir de este primer poema luego tanto utilizará. Machado dramatiza el monólogo interior, personificando bien en la fuente, la tarde o la noche los interlocutores que tiene frente a si y que le sirven de interlocutor imaginario. Cfr. SÁNCHEZ BARBUDO, A. (1967): Los poemas de Antonio Machado. Los temas, el sentimiento y la expresión, Barcelona, Lumen, p. 85. 
lenguaje sensual, colorista, fresco, brillante y sonoro, muy propio del simbolismo, y que constrata con el empleado en la descripción física del espacio poético. Así en el texto apreciamos que de la fuente mana: la sonora/copla borbollante del agua cantora, (v.1-2. estrofa $3^{\mathrm{a}}$ ), esta adjetivación sonora y sensual se completa con la metáforas con las que el poeta nos presenta al líquido elemento: claro cristal de alegría, (v.1, estrofa $9^{\mathrm{a}}$ ) y bellos espejos cantores, (v. 1, estrofa 10 $0^{\mathrm{a}}$ ). Recurre de nuevo a la metáfora para decirnos que la fuente tiene: una lengua encantada - el agua- (v 3. estrofa $10^{\mathrm{a}}$ ) con la que le cuenta al poeta su alegre leyenda olvidada, (v. 4, estrofa $\left.10^{\mathrm{a}}\right)$ y a la que el poeta besó cual amada: tus labios besaron mi linfa serena, (v. 3. estrofa $12^{\mathrm{a}}$ ).

Gracias a esta antítesis entre la descripción de un marco físico desolado, triste y amargo, que representa el pasado, y el recuerdo, en y desde el presente, de una experiencia vital alegre, feliz y gozosa se refuerza el deseo de Machado por rescatar del pasado y devolver al presente aquellas emociones que tanto antes como ahora le siguen haciendo feliz. Emociones y vibraciones gozosas que resucitan merced al uso de un despliegue recursos lingüísticos que hacen del poema un perfecto cuadro impresionista. Por ello en la lectura del texto hay que dejarse llevar por lo que cada uno es capaz de sentir, de evocar, de imaginar dejando a un lado lo nuestra mente piense.

A lo largo de todo el poema asistimos a un viaje e ida y vuelta entre el pasado y el presente, el cual es simbolizado por el siguiente quiasmo:

sueño lejano/canto presente (v. 2, estrofa $4^{\mathrm{a}}$ )

copla (presente)/ copla lejana ( v. 3 , estrofa $5^{\mathrm{a}}$ )

Para el poeta todo ocurre en el instante presente, pues gracias al canto del agua este mismo momento antes vivido se funde con el tiempo actual. El monótono fluir del agua simboliza la atemporalidad de lo que acontece: lo mismo que el agua es siempre igual, pero siempre distinta, los recuerdos se evocan en el presente con la misma fuerza e intensidad con las que se vivieron los mismos hechos en el pasado. Es decir; que, la fuentesabe que una clara tarde de verano; (v. 1-2, estrofa $1^{\text {a }}$ ) el "yo" del poeta ya se había acercado a ella para besar sus aguas, manifestando entonces el mismo deseo pasional que ahora expresa su "yo" lírico. Los dos momentos se funden en uno, el pasado entra a ser parte del presente, se confunde con él. Y es que en definitiva, tal como señala Daniela Capra:

Una vez más el pasado, o mejor dicho, la melancolía de lo que fue, entra en el presente, con un juego de presencia y ausencia que se afirma en el momento en que se niega. Para escapar de ello, el yo lírico se despide para siempre de la fuente: "Adiós para siempre la fuente sonora,/ del parque dormido la eterna cantora." (Capra, 2003: 3) 
Tomamos ahora como objeto de nuestro análisis el poema XLIII titulado: Era una mañana y abril sonreía. ${ }^{10}$ Al igual que en el caso anterior, se transcriben aquí las primeras estrofas y para la lectura del texto completo se remite al lector a las pp. 147148 de la Edición de Geoffrey Ribbans:
Mañana de abril
Era una mañana y abril sonreía.
Frente al horizonte dorado moría
la luna, muy blanca y opaca; tras ella, cual tenue ligera quimera, corría
la nube que apenas enturbia una estrella.
Como sonreía la rosa mañana
al sol del oriente abrí mi ventana;
$\mathrm{y}$ en mi triste alcoba penetró el oriente
en canto de alondras, en risa de fuente
$\mathrm{y}$ en suave perfume de flora temprana.

\section{A. Concreciones de la temporalidad que configuran el tema central del poema:}

El eje estructural del poema se sustenta sobre la antítesis mañana/tarde como límites temporales del contenido poético. Machado nos abre su mundo interior: $m i$ triste alcoba, (v. 3. estrofa $2^{\mathrm{a}}$ ), del cual sale por un instante para ponerse en contacto con los elementos naturales que le circundan. De aquí surge el diálogo entre el mundo interior del poeta - yo lírico- y el mundo exterior - el vosotros- que es representado por todos los elementos naturales: mañana, sol, alondra, perfume, flores, campanas, fuente, etc. El poeta abandona su ensimismamiento por un instante para buscar en la Naturaleza estímulos para sentirse feliz y alegre como lo fue antes en su juventud. Los hechos presentados en el texto transcurren entre el antes, entendido como el eterno anhelo de ser feliz que mantuvo la esperanza del poeta hasta la inesperada muerte de su esposa Leonor, y el hoy, momento en el Machado le pregunta a la tarde si existe alguna posibilidad de que la alegría llene de nuevo su corazón. Pregunta cuya respuesta no deja lugar a la duda, a tenor de lo que la tarde le contesta:

Pregunté a la tarde de abril que moría:

¿Al fin la alegría se acerca a mi casa?

La tarde de abril sonrió: La alegría

pasó por tu puerta - y luego sombría:

Pasó por tu puerta. Dos veces no pasa.

$\left(\text { Estrofa } 4^{\mathrm{a}}\right)^{11}$

10 Poema que en Soledades, (1903) se titula "Mai piú" y está dedicado a Francisco Villaespesa.

11 La negrita es mía. 
Mediante la oposición temporal, que es enfatizada por los tiempos verbales: pasó frente a pasa queda muy clara la importancia de la temporalidad como esquema articilador del texto. El poeta ya tuvo su oportunidad de ser feliz, de estar alegre. Ya contó con su efímero momento de amor y de gozo, pero esta dicha ya no puede volver por más que se busque de nuevo en el presente.

$\mathrm{Y}$ este encuentro entre el "yo" del poeta y el mundo exterior se produce en un marco natural vivo, sonoro, colorista, sensual; es decir, claramente simbolista, pues tal como nos precisa J. M. Aguirre:

Machado buscaba una poesía centrada en el análisis del "yo, no en su anécdota, sino en cuanto poseedor de sentimientos; porque creía, como los simbolistas, que el sentimiento es lo más personal y, al mismo tiempo, universal que el hombre posee, pues con él pueden comulgar otros hombres. La realidad sólo le interesaba en cuanto podía producir esos sentimientos o, sobre todo, ofrecer material para construir símbolos. (Aguirre, 1973: 54)

Se trata de una descripción del espacio natural en la que todos sus elementos llegan al lector a través de los sentidos; a saber: la vista: horizonte dorado, (v.2, estrofa $\left.1^{\mathrm{a}}\right)$, luna blanca y opaca, (v.3, estrofa $\left.1^{\mathrm{a}}\right)$, rosa mañana, (v.1, estrofa $\left.2^{\mathrm{a}}\right)$; el olfato: suave perfume de flora temprana, ( v. 4, estrofa $2^{\mathrm{a}}$ ), viento traía perfume de rosas, ( v. 3-4, estrofa $3^{\mathrm{a}}$ ), de rosas aromado aliento, (v. 2, estrofa $4^{\mathrm{a}}$ ); el oído: el canto de alondras, (v. 4, estrofa $2^{\mathrm{a}}$ ), doblar de campanas, ( v.1, estrofa $\left.4^{\mathrm{a}}\right)$. De todos estos elementos recibe el poeta llamadas, estímulos, sensaciones, impresiones, los cuales desencandenan en él un conjunto de emociones con las que pretende vivir en el instante presente los escasos momentos felices de los que disfrutó en el pasado. En otras palabras, Machado pretende buscar fuera de su "yo" la colaboración necesaria para que sus poemas sean un claro reflejo de lo incompleto e insatisfecho que él se siente, pues en su opinión:

El sentimiento no es una creación del sujeto individual, una elaboración cordial del yo con los materiales del mundo exterior. Hay siempre una colaboración con el tú, es decir colaboración de otros sujetos. Por ello no se puede llegar a esta simple fórmula: mi corazón frente al paisaje produce sentimientos, y una vez producidos por medio del lenguaje los comunico a mi prójimo. Mi sentimiento no es, en suma, exclusivamente mío, sino más bien nuestro. (Machado, 1925: 79)

\section{B. Elementos simbólicos que evidencian la temporalidad a lo largo del poema:}

Recurre aquí Machado a dos secuencias temporales: la maña y la tarde para dotar de temporalidad al texto. La mañana simboliza el inicio, la apertura, la esperanza, la búsqueda de algo nuevo; mientras que, la tarde representa a la tristeza, la angustia, la pena al descubrir que el tiempo de la alegría ya ha pasado y que jamás volverá. Este mismo lapsus temporal divide al poema en dos partes muy bien diferenciadas. En las dos primeras estrofas se nos ofrece la apertura del "yo" lírico hacia los elementos externos de la Naturaleza que le rodean y que reclaman su atención: la mañana de abril/ la luna blanca y opaca/ la nubel la estrella, (estrofa $1^{\mathrm{a}}$ ). La rosa mañana/ el sol 
del orientel el canto de alondral la risa de fuentel el suave perfumel de flora temprana. (estrofa $2^{\mathrm{a}}$ ). Todos estos elementos pertenecen al ámbito de la alegría, del gozo y de la felicidad. Por contra, en las dos segundas el contenido significativo de los versos es justo el contrario: la tarde de melancolíal el doblar de campanas, (estrofa $3^{\mathrm{a}}$ ). Las campanas lejanas, llorosas/ qué dicen al viento, (estrofa $4^{\mathrm{a}}$ ). Estos elementos transmiten al lector la melancolía y la tristeza provocadas por la imposibilidad del poeta de recuperar la alegría pasada. Una imposibilidad que se ratifica en la última estrofa, en la cual la contestación de la tarde acaba con todas las esperanzas del poeta: la alegría pasó por tu puertal dos veces no pasa, ( vv. 4-5, estrofa $5^{\mathrm{a}}$ ).

Gracias a esta división bipartita se acentúa la carga simbólica de muchos de los términos que se usan en los versos. El poeta concentra la tensión lírica en las dos primeras estrofas con la esperanza de que por fin le llegará la dicha deseada. Pero nuestro autor pretende ignorar los presagios negativos: luna blanca - pero - opaca, (v. 3, estrofa $1^{\mathrm{a}}$ ) y mantener su confianza en que al fin la felicidad le llegará. Sin embargo, la tristeza y la desilusión se apoderan de él al comprobar que aquella felicidad que en el pasado -tiempo pasado - estuvo viva en su alma, ya no volverátiempo futuro- . Y esta tensión dialéctica entre la ilusión de lo que fue y la desesperanza ante lo que ya no volverá a ser se traslada a lo versos por medio de algunos términos, cuya carga simbólica pasamos ahora a precisar:

1. el viento:_aquí representa el nexo entre el pasado (los recuerdos, las vivencias, los momentos alegres, la juventud), el presente (momento en el que se evoca en los versos) y el futuro ( tiempo para el deseo, para el anhelo de que las sensaciones positivas se puedan repetir). Esta importancia nexual del viento queda expresa en los siguientes versos:

Yo abrí las ventanas

de mi casa al viento...El viento traía

perfume de rosas, doblar de campanas...

(vv. 3-4, estrofa $4^{\mathrm{a}}$ )

Y son estos perfumes, este tañer de lejanas campanas, este suave aroma de las rosas los que hacen salir al poeta de su yo interior y buscar la comunicación con el mundo exterior, pues tal como precisa Lisa Bock de Beher:

La escritura - y por tanto la creación poética - se puede considerar como una peregrinación del interior hacia el exterior en la que cada escritor debe despojarse sus sentimientos en un espacio y en un tiempo determinados. En este contexto el lenguaje ha perdido toda su función mimética y está destinado a transformar en ficción todo lo que toca. ( Block de Beher, 1994: 20)

2. el huerto:_es símbolo de la ilusión de los años infantiles y juveniles. Son los sueños que atesoran los recuerdos que el poeta quiere hacer presentes y por eso le pregunta con premura a la tarde de abril: ¿dónde están esos huertos floridos de rosas?, (v. 3, estrofa $4^{a}$ ). Pregunta que interpretada en clave temporal equivale a 
cuestionarse, a buscar en su recuerdo los "otros huertos" en los que de niño y joven fue feliz. Ahora, en el instante presente, con la ventana de su alcoba abierta, el poeta quiere rememorar lo pasado, pero el paso repentino de la mañana a la tarde no le permite ninguna reacción y para cuando quiere darse cuenta, ya: la alegría pasó por su puerta, (vv. 3.4, estrofa $\left.5^{\mathrm{a}}\right){ }^{12}$

\section{B. Recursos lingüísticos propios de una lírica natural, sencilla y trasparente:}

De una lectura atenta del texto se deduce que Machado se preocupó de seleccionar con esmero tanto los epítetos y los calificativo como sus correspondientes sustantivos, sobre los que descansa la acción. El poeta, embriagado por la llegada de la primavera, le pregunta a la tarde - se pregunta a si mismo - si los floridos huertos de su ayer, vuelven hoy con la misma alegría. La respuesta de la tarde le desengaña, ya nada puede volver a ser lo que fue. Pues bien, hecha esta selección intencionada de los términos, veamos ahora cómo los mismos contribuyen a la creación de un lenguaje poético cercano al lector:

\section{a. El uso de epítetos y calificativos para describir el marco físico de la acción:}

En la selección antes aludida dominan los epítetos y de los 17 adjetivos tan sólo 3 son pospuestos, con ello queda patente que el poeta centra la descripción en los objetos mismos: rosa mañana, (v.1, estrofa $2^{\mathrm{a}}$ ), triste alcoba, (v.3, estrofa $2^{\mathrm{a}}$ ), clara tarde, (v. 1, estrofa $3^{\mathrm{a}}$ ) y hace menos énfasis en los llamados adjetivos del discurso: canto de alondras, (v. 4, estrofa, $2^{\mathrm{a}}$ ); risa de fuente, (v.4, estrofa $2^{\mathrm{a}}$ ), doblar de campanas, (v.1, estrofa $\left.4^{\mathrm{a}}\right)$, risa de fuente, ( v. 4, estrofa $2^{\mathrm{a}}$ ). Pues bien, sea con los epítetos o con los adjetivos, el poeta nos pinta un escenario natural plenamente simbolista.

\section{b. El uso de los tiempos verbales como recurso que facilita el diálogo:}

Machado despliega a lo largo del poema la técnica del dialogo, gracias a la cual la relación dialéctica entre el pasado y el presente vuelve a sus versos. Se trata, una vez más, de un juego de contrarios que acentúa el carácter intimista y subjetivo de este poema en concreto y de gran parte de los incluidos en Soledades, galerías y otros poemas, (1907), pues tal como señala Aurora Albornoz en relación a este libro:

A pesar de los lugares comunes fruto de la influencia modernista, hay ciertas notas de intimismo que lo sitúan dentro de la realidad. De la realidad soñada, naturalmente. Hablamos de un libro que no crea un mundo fantástico alejado de lo real intencionadamente, sino que crea un mundo íntimo, tan profundamente íntimo,

12 Tal como señala Daniela Capra, el paso de la mañana a la tarde: no es tan repentino en la versión original de este poema, incluida en la edición de Soledades, (1903) con el título Mai piú, porque los versos eliminados, bastante narrativos, contaban que el poeta, tras saber de la mañana que un peregrino (la alegría) iba a llegar pero estaba lejano todavía, cierra la ventana y se duerme. Al despertarse, ya es la tarde: el peregrino pasó y no volverá a pasar. (Cfr. Capra, Daniela, art. cit. nota $10^{\mathrm{a}}$ ) 
tan profundamente temporal que alcanza por ello la universalidad y la eternidad, (Albornoz, 1961: 157)

Y en este diálogo entre el "yo" del poeta y los elementos naturales, el uso de los tiempos verbales se convierte en un recurso lingüístico de primer orden, pues con ellos se subraya la importancia de la temporalidad en el texto. Así, con el uso del pretérito imperfecto: era una mañana y abril sonreía, (v.1, estrofa, $1^{\mathrm{a}}$ ), horizonte dorado moría, (v. 2, estrofa $1^{\mathrm{a}}$ ), luna blanca corría, ( v.4, estrofa $1^{\mathrm{a}}$ ) se ubica la acción en el tiempo y en el espacio, a la par que se crea en marco físico para la misma. Por contra, en la segunda estrofa el poeta recurre al pretérito indefinido: abrí mi ventana, (v. 2, estrofa $2^{\mathrm{a}}$ ), penetró el oriente, (v. 3, estrofa $2^{\mathrm{a}}$ ) para señalar dos acciones puntuales. El escritor recurre a los imperfectos para poner al lector en situación y para introducirle en un diálogo en el que usa el presente absoluto como forma propia de la conversación: ¿dónde está los huertos floridos de rosas?, (v.3, estrofa $4^{\mathrm{a}}$ ), ¿qué dicen las dulces campañas al viento?, (v.4, estrofa $4^{\mathrm{a}}$ ), ¿ al fin la alegría se acerca a mi casa, (v. 2, estrofa $5^{\mathrm{a}}$ ). Con este uso del presente se refuerza el carácter atemporal de las preguntas, que a fin de cuentas no son otra cosa que la expresión de las inquietudes constantes del poeta.

En síntesis, podemos decir que Machado utiliza en el poema una lenguaje vivo, fluido, trasparente, gracias al cual el lector percibe dos realidades temporales: la mañana, que es el presente y la tarde, que es el pasado visto desde distintas perspectivas.

Terminamos nuestro recorrido con el análisis de uno de los poemas más representativos de Soledades, galerías y otros poemas, (1907), nos referimos al poema I, titulado El viajero. En este poema, Machado establece un diálogo cordial con todo el universo, convirtiendo a los lectores en partícipes de esa comunicación universal. Esta habilidad del poeta para hacernos ver su modo de entender el mundo a través de su poesía requiere del uso de ciertas técnicas, algunas de las cuales saldrán a la luz en nuestro análisis. Para empezar, y como en los casos anteriores, transcribimos para el lector las dos primeras estrofas y le remitimos para el resto a las páginas 82-83 de la Edición de Goeffrey Ribbans ya mecionada:

\footnotetext{
El viajero

Está en la sala familiar, sombría, y entre nosotros, el querido hermano que en el sueño infantil de un claro día vimos partir hacia un país lejano.

Hoy tiene ya las sienes plateadas, un gris mechón sobre la angosta frente; y la fría inquietud de sus miradas revela un alma casi toda ausente.
} 


\section{A. Concreciones de la temporalidad que configuran el tema central del poema:}

Insiste nuestro autor en trasladar a este poema su obsesión por el tiempo, y lo hace mediante la oposición entre lo que pasa y lo que permanece, siendo evidente lo que pasa y sólo imaginado o esperado aquello que resiste al tiempo. Sobre esta oposición de momentos temporales se asienta el contenido de este poema, sabiendo, de antemano, que el tema de la emigración y del retorno tiene en Machado un componente vital muy destacado, tanto por las estancias americanas de su abuelo, Manuel Machado Núñez, como las de su padre y Joaquín, su hermano menor. Esta tensión entre lo que se va y lo que se queda es recreada por el autor mediante un conjunto de símbolos e iconos propios de la poesía simbolista, los cuales tienen como propósito sugerir, provocar la imaginación, evocar; eso sí, siempre desde el fondo del alma y de las cosas. Hablamos aquí de una estética poética que, en opinión de Vicente Tusón y Fernando Lázaro, fue adoptada por nuestro poeta pues para él - igual que para Rimbaud, Baudelaire y Mallarmé:

El culto a la belleza no les satisface, y sin abandonar por ello las metas estéticas , quieren ir más allá de las apariencias. Para ellos, el mundo sensible sólo refleja - es símbolo - de realidades escondidas, y la misión del poeta es descubrirlas. De aquí que sus versos se pueblen de misterio, de sueños, de símbolos que dan al hombre el movimiento. En suma, se trata de una poesía que va por otros derroteros, que se propone sacar a la luz el fondo del alma o de las cosas. ( Tusón y Lázaro, 1981: 48)

Y precisamente sacar a la luz su "yo" íntimo y ponerlo en contacto con los "otros yos" es lo que trata Machado de hacer en este poema. Nuestro poeta nos muestra su "otro yo" - su hermano - con el que conversa gracias a la técnica del monólogo interior. Una conversación con la que, en opinión de Domingo Ynduraín:

Machado se reconoce en el otro y se interesa por él porque al mismo tiempo es y no es igual al "yo". Se trata en este poema de otra paradoja, pues nuestro poeta está suponiendo y proyectando en el hermano los mismos problemas que le afectan a él. (Ynduraín, 1990: 128)

Este doble del "yo" del poeta que busca a su otro "yo" en un hermano imaginario queda poetizado en el texto por medio de un símbolo netamente temporal: el viaje y el viajero. Ambos términos son recurrentes en el poeta, el cual los usa para exponernos los cambios físicos y psíquicos que ha experimentado el viajero desde su salida hasta su regreso. De nuevo se recurre a la antítesis entre el pasado - infancia, juventud, vida feliz:

que el sueño feliz de un claro día vimos partir hacia un país lejano.

(vv. 3.4, estrofa $1^{\mathrm{a}}$ )

y el presente - senectud, tristeza, pena: 
Hoy tiene las sienes plateadas, un gris mechón sobre la angosta frente;

Machado fusiona temporalmente dos viajes; de un lado, el viaje ficticio - del sueño infantil - y, de otro, el viaje real - propio de su vida. Por medio de la imagen del viajero el poeta nos introduce en un sueño instantáneo y revelador del recorrido de toda su vida.

\section{$B$. Elementos simbólicos que evidencian la temporalidad a lo largo del poema:}

El valor que Machado concede al uso de símbolos, para subrayar la temporalidad del poema, es refrendado por Antonio Serrano en el siguiente comentario:

La tantas veces subrayada temporalidad de la poesía de Antonio Machado explica la temprana aparición de los símbolos del poeta en relación con el tiempo: el agua que corre, el viajero, el camino, los momentos del día, las estaciones del año, etc. Todos los elementos poéticos en analogía con el tema del tiempo y la correspondiente interpretación se unen difusamente en el espíritu del poeta como un acorde que difunde temáticamente toda su obra: el acorde del tiempo, e inevitablemente de la muerte. (Serrano, 2000: 2)

En esta cita encontramos el contexto adecuado para presentar alguno de dichos símbolos:

a. El rostro del viajero: en el rostro se concentran los elementos temporales más significativos del poema: el rostro del hermano se ilumina, (v.1, estrofa $4^{\mathrm{a}}$ ). Este rostro es el del poeta, el cual al iluminarse nos muestra los efectos que el paso del tiempo ha provocado en su físico: hoy tiene ya las sienes plateadas, (v.1, estrofa $2^{\mathrm{a}}$ ). El pasado lejano y triste se contempla desde el hoy, a la par que el uso del adverbio temporal "ya" nos hace sentir que este tiempo presente está cargado con toda la nostalgia del pasado. Un pasado que, una vez más es simbolizado por la tarde la cual se contempla: tras los húmedos cristales, (v. 3, estrofa $3^{\mathrm{a}}$ )

b. El tic-tac del reloj: representa una alusión clara y directa al paso del tiempo: en la tristeza del hogar golpea/ el tic-tac del reloj, (v.3, estrofa $\left.9^{a}\right)$. El reloj simboliza el paso inexorable del tiempo real, el tiempo que nos va conduciendo hacia la muerte El paso del tiempo exterior nos hace recordar el tiempo interior: lo ya vivido, y lo hace con una monotonía insoportable.

\section{Recursos lingüísticos propios de una lírica natural, sencilla y trasparente:}

De lo antes indicado se desprende que, tal como señala Carlos Bousoño: todo el poema está rafageado por signos de sugestión que evocan la amenazante temporalidad de la existencia humana y la pesadumbre que esa temporalidad despierta en el "yo" hablante del poema. (Bousoño, 1970: 138). Y esta temporalidad se presenta al lector por medio de un lenguaje poético cargado de evocaciones sensoriales y propio de la estética simbolista. 
Desde la prosoprografía con la que se nos describe la apariencia física del viajero que: tiene sus sienes plateadas/gris mechón sobre la frente, (v. 1-2, estrofa, $2^{\mathrm{a}}$ ) a la etopeya con la se nos da cuenta de su actitud ensimismada y ausente: revela un alma casi toda ausente, (v. 4, estrofa $2^{\mathrm{a}}$ ), pasando por el efecto sonoro y musical que provoca en el lector la alternancia de epítetos y calificativos: parque mustió y viejo, (v.2, estrofa $3^{\mathrm{a}}$ ), blanca juventud, (v. 3, estrofa $5^{\mathrm{a}}$ ), olorosas ramas, (v. 2-3, estrofa, $\left.5^{\mathrm{a}}\right)$, blancas rosas, (v. 3, estrofa $\left.5^{\mathrm{a}}\right)$, semblante pálido, (v. 4, estrofa $6^{\mathrm{a}}$ ) para llegar a la metáfora con que se alude al monótono transcurrir del tiempo: en la tristeza del hogar golpea/ el tic-tac del reloj, ( vv. 3-4, $9^{\mathrm{a}}$ ). Todos los recursos contribuyen a configurar un lenguaje que nos acerca a una realidad más soñada que vivida. Por ello, el lector se queda extasiado ante lo que tiene más visos de irreal que de cierto, pues no olvidemos que tal como precisa Ramón de Zubiría: Machado busca en el sueño una forma provisional de conocimiento y se refugia en él como en un paraíso intemporal. ( Zubiria, 1959: 203). Y esta conversión de la poesía en un escenario para el sueño es lograda por nuestro poeta gracias al uso de un lenguaje en el que las palabras evocan sensaciones y transmiten al lector sentimientos mucho antes que ideas.

\section{Conclusión}

A lo largo de estas páginas ha quedado patente que la temporalidad, como concepto filosófico, forma parte esencial del pensamiento y del quehacer poético de Machado. Y esta conversión de la poesía en un arte temporal es llevada a cabo por nuestro autor mediante el uso de un lenguaje cargado de símbolos y recuerdos que miran al pasado desde el presente. Este es el mayor logro que esta colaboración pone de relieve; a saber: cómo el poeta andaluz fue capaz de convertir el pasado en un presente inmediato, cómo logró fundir la dimensión del tiempo lógico - pasado, presente y futuro - en una sola realidad, en un instante presente que desde el hoy se pretende eternizar. Y lo logró hasta tal punto que el matrimonio entre la filosofía y la poesía dio sus frutos en forma de versos, en los cuales la esencia del ser es lo que se mantiene, aunque cambie su sustancia.

Y si de algún modo la temporalidad bergsoniana encuentra acomodo el los versos de Machado, ello se debe a la puesta en práctica de una estética claramente simbolista con la que se subrayan las relaciones entre el hombre y la Naturaleza. Esta mirada al mundo exterior hace que el poeta salga de su ensimismamiento y se abra a un diálogo universal como forma de comunicación con todos los seres humanos. Una comunión que refuerza su concepción de la poesía como "palabra en el tiempo", pues por medio de sus versos nuestro poeta pretende reflejar, en un instante, todos aquellos momentos de su tiempo vital que jamás deberán ser olvidados por quienes con él se comuniquen en este tiempo presente y en los tiempos venideros.

Confiamos en que esta modesta aportación sirva pasa suscitar la curiosidad del lector y el interés del amante de la lírica machadiana. A partir de aquí queda mucho por hacer para sacar a la luz todo lo que dio de sí el empeño de Machado por trasladar a sus versos un pensamiento filosófico tan bien estructurado como meditado y sustancioso. 


\section{OBRAS CITADAS}

ALBORNOZ, A. (1961): "Miguel de Unamuno y Antonio Machado" en La Torre, 9, Revista de la Universidad de Puerto Rico.

AYALA, F. (1975): El escritor y su imagen: Ortega y Gasset, Azorín, Valle Inclán y Antonio Machado, Madrid, Guadarrama.

BLOCK DE BEHER, L. (1994): Una retórica del silencio, Buenos Aires, Siglo XXI.

BOUSOÑO, C. (1970): Teoría de la expresión literaria, Madrid, Gredos.

CAPRA, D. (2003): "Presencia y ausencia en Soledades, galerías y otros poema, en Artifara, 3.

DIEGO, G. (1949): "Tempo lento en Antonio Machado", en Antonio Machado: el escritor y la crítica. Ed. Ricardo Gullón y Allen W. Phillips, Madrid, Taurus, 1979.

GULLÓN, R. (1949): "Lenguaje, humanismo y tiempo en Antonio Machado", en Cuadernos Hispanoamericanos, 11-12.

GULLÓN, R. (1986): Una poética para Antonio Machado, Madrid, Espasa-Calpe.

GULLÓN, R. (1987): Espacios poéticos de Antonio Machado, Madrid, Cátedra.

GICOVATE, B. (1964): "La evolución poética de Antonio Machado", en Antonio Machado: el escritor y la crítica. De. de Ricardo Gullón y Allen W. Phillips, Madrid, Taurus, 1979.

ISER, W. (1997): "La ficcionalización”, en Teoría de la ficción literaria, Madrid, Lectura.

JAUS, H. R. (1986): Experiencia estética y mistica de la literatura. Madrid, Taurus,

LÓPEZ-MORILLAS, J. (1961): “Antonio Machado y la interpretación temporal de la poesía", en Antonio Machado: el escritor y la crítica. Ed. Ricardo Gullón y Allen W. Phillips, Madrid, Taurus.

MACHADO, A. 1936, (1983): Poesías Completas, Madrid, Espasa-Calpe.

MACHADO, A. (1940): Obras Completas, México. Ed. Séneca.

MACHADO, A. 1924, (1964): "Problemas de la lírica", en Antonio Machado: obra, poesía y prosa, Buenos Aires, Losada.

OLCAY, T. (2005): La recepción de la poesía de Antonio Machado desde el punto de vista del "yo" lírico y la temporalidad en el siglo XX. Tesis Doctoral. Universidad de Ankara.

RIBBANS, G. (1998): "De Soledades a Campos de Castilla", en Abel Martín, Revista digital. Sito web:www.abelmartin.com

SARTRE, J. P: (1948): Situations, II, París, Gallimard.

SESÉ, B. (1980): Antonio Machado: el poeta, el hombre, el pensador, Madrid, Gredos.

SERRANO, A. (2000): "La obra de Antonio Machado", en Abel Martín, Revista virtual.

TUSÓN, V Y LÁZARO, F. (1981): Literatura española, Madrid, Anaya.

VÁZQUEZ MEDEL, M. A. (1997): “Antonio Machado: poesía última y ultimidad de la poesía", en CAUCE. Revista de Filología y su Didáctica, 20-21.

YNDURAIN, D. (1990): "Las voces apócrifas de Antonio Machado", en Antonio Machado, Hoy, Sevilla, Alfar.

ZUBIRIA, R. (1959): La poesía de Antonio Machado, Madrid. 